\title{
Opinia pacjentów $w$ aspekcie radzenia sobie z bólem po zabiegach operacyjnych
}

\author{
Coping with pain after surgical procedure - patients' \\ experience
}

\section{JOANNA BLUMA ${ }^{1}$, AGNIESZKA KRÓLIKOWSKA ${ }^{2}$, TERESA SIEMIANOWSKA ${ }^{3}$, IWONA CZARNIECKA ${ }^{3}$}

${ }^{1}$ Szpital Wielospecjalistyczny im. Dra Ludwika Błażka w Inowrocławiu

210 Wojskowy Szpital Kliniczny z Polikliniką w Bydgoszczy

3 Wojewódzki Szpital Specjalistyczny im. błogosławionego księdza Jerzego Popiełuszki we Włocławku

DOI: http://dx.doi.org/10.21784/IwP.2017.021

ISSN: 2451-1846

\section{Streszczenie:}

Wstęp. Ból określa się jako stan patofizjologiczny, wymagający specjalistycznego postępowania terapeutycznego, a dobór właściwych środków przeciwbólowych zależy od wiedzy na temat jego mechanizmów. Przeprowadzanie badań na temat strategii radzenia sobie $\mathrm{z}$ bólem pooperacyjnym przez pacjentów hospitalizowanych $\mathrm{w}$ oddziale chirurgii daje możliwość na modyfikację dotychczasowych działań i wdrożenie takich rozwiązań przez zespół terapeutyczny, które są najwyżej oceniane przez odbiorców świadczeń.

Cel. Celem pracy jest zbadanie opinii pacjentów poddanych zabiegom operacyjnym $\mathrm{w}$ aspekcie radzenia sobie z bólem. Analiza obejmuje ocenę przekonań i strategii radzenia sobie $\mathrm{z}$ bólem $\mathrm{w}$ zależności od przeprowadzonego zabiegu operacyjnego.

Materiał i metody. Badaniem objęto wśród 60 pacjentów (kobiety i mężczyźni w wieku $\geq 18$ lat) Oddziału Chirurgii Ogólnej, Chirurgii Onkologicznej i Chemioterapii w Szpitalu Wielospecjalistycznym im. Dra Ludwika Błażka w Inowrocławiu. Pomiaru dokonano przy użyciu testu t- 
Studenta oraz testu ANOVA Kruskala Wallisa. Analizę statystyczną przeprowadzono przy użyciu programu Statistica 10.0. Przyjęto poziom istotności $\mathrm{p} \leq 0,05$.

Wyniki. Zaprezentowane wyniki badań przedstawiają różnice w ocenie przekonań i strategii radzenia sobie z bólem biorąc pod uwagę rodzaj przeprowadzonego zabiegu operacyjnego.

Wnioski. Rodzaj zabiegu operacyjnego nie wpływał na istotne różnice w wyborze strategii i sposobów radzenia sobie z bólem przez badanych poddanych określonym zabiegom chirurgicznym.

Słowa kluczowe: ból, strategie radzenia sobie z bólem, ból pooperacyjny

\begin{abstract}
:
Introduction. Pain is defined as a pathophysiological mechanism and requires expertise theraupetic meassures. Careful selectiona and the right choice of pain relief depends on the knowlege of the nature of pain. Study devoted to strategies of pain management among hospitalized patients from surgery department enable the modification of current meassures and the implementation of such activities that are highly assesed by patients.

Aim. The aim of the study is to asses the opinion of patients who underwent a surgery and their views on coping with pain. The study includes the assement of patients' views and strategies of pain management depending on surgery.
\end{abstract}

Material and methods. The study comprised of 60 patients ( men and women aged $\geq 18$ ) from general and oncological surgery as well as chemotherapy department in Multi-Specialist Hospital of $\mathrm{Dr}$ Ludwik Błażek in Inowrocław. Meassuerments were taken by means of t-Student test and ANOVA Kruskal Wallis's test.Sttistical analysis comprised Statistica 10.0 programme. The level of significance was set at $p \leq 0,05$.

Results. Presented results show different views and strategies of pain management depending on surgery.

Conclusions. The nature of surgical procedure does not sygnificantly affect the choice of pain managent strategies among patients who underwent a given surgery.

Keywords: pain, pain management strategies, postsurgical pain 


\section{Wstęp}

Ból określany jest jako stan patofizjologiczny, który wymaga wykwalifikowanego postępowania terapeutycznego. Natomiast dobór właściwych środków przeciwbólowych zależy od wiedzy na temat jego mechanizmów [34]. Międzynarodowe Towarzystwo Badania Bólu (IASP, International Association for the Study Of Pain), podaje że ból to „przykre i negatywne wrażenie zmysłowe i emocjonalne, powstające pod wpływem bodźców uszkadzających tkanki lub zagrażających ich uszkodzeniem" [1].

Ból po zabiegach operacyjnych spowodowany jest śródoperacyjnym uszkodzeniem tkanek i narządów. Intensywność odczuwanego przez pacjenta bólu jest zwykle wprost proporcjonalna do rozległości zabiegu operacyjnego. Ważnym aspektem, który warto dostrzec jest fakt, że istnieją indywidualne różnice osobnicze w odpowiedzi na doznania bólowe, wynikające z wielu czynników, takich jak: uwarunkowania genetyczne, kulturowe, wiek czy też płeć. Stopień odczuwania bólu zależy także od ogólnego stanu zdrowia, poprzednich doświadczeń bólowych oraz stanu emocjonalnego przed zabiegiem operacyjnym [2].

Mimo różnorodności stosowanych metod leczniczych, w tym dużych możliwości uśmierzania i walki z bólem, często te techniki stosowane są $\mathrm{w}$ znikomym zakresie. Leczenie bólu w Polsce wymaga szeregu zmian, z uwagi na to Polskie Towarzystwo Badania Bólu rozpoczęło prace nad wprowadzeniem standardów leczenia bólu pooperacyjnego. W czerwcu 2008 Towarzystwo opracowało zalecenia uśmierzania bólu, które aktualizowano w 2011 roku. Obecne zalecenia zawierają założenia EBM (Evidence-Based Medicine) czyli medycyny, która oparta jest na dowodach naukowych. Terapia bólu pooperacyjnego opiera się na współpracy w zespole interdyscyplinarnym, $\mathrm{w}$ tym $\mathrm{z}$ anestezjologiem, a także lekarzem prowadzącym (np. chirurgiem), według indywidualnej karty zleceń 
lekarskich. W przypadkach doraźnych pielęgniarka może podać lek przeciwbólowy, nawet bez zlecenia lekarskiego [3,4,5]. Na szczególną uwagę zasługuje fakt, że badania prowadzone przez polskich naukowców sugerują, że pielęgniarki nie zawsze mają wiedzę z zakresu postępowania przeciwbólowego oraz ubocznych skutków działania leków, co powinno ulec zmianie [3].

Celem pracy jest zbadanie opinii pacjentów poddanych zabiegom operacyjnym $\mathrm{w}$ aspekcie radzenia sobie z bólem. Analiza obejmuje ocenę przekonań i strategii radzenia sobie $\mathrm{z}$ bólem w zależności od wieku badanych.

\section{Materiał i metody}

Badaniem objęto wśród 60 pacjentów Oddziału Chirurgii Ogólnej, Chirurgii Onkologicznej i Chemioterapii w Szpitalu Wielospecjalistycznym im. Dra Ludwika Błażka w Inowrocławiu. W badanej grupie 30 osób (50\%) stanowili mężczyźni, a 30 osób $(50 \%)$ - kobiety

W badanej grupie z przepukliną pachwinową znajdowało się 15 (50\%) mężczyzn i 15 (50\%) kobiet. Podobnie w grupie 30 osób z kamicą znajdowało się 15 (50\%) mężczyzn i 15 (50\%) kobiet. Wśród badanych znajdowało się 20 (33.3\%) osób w wieku 25-45 lat, 20 osób (33.3\%) było w wieku 45-60 lat i 20 osób (33.3\%) miało powyżej 60 lat.

W grupie 30 osób z przepukliną pachwinową znajdowało się 13 (43\%) osób w wieku 25-45 lat, 13 (43\%) było w wieku 45-60 lat (43\%), a 4 osoby (14\%) miały powyżej 60 lat.

W grupie 30 osób z kamicą pęcherzyka żółciowego znajdowało się 7 (23\%) osób w wieku 25-45 lat, 7 (23\%) było w wieku 45-60 lat (43\%), a 16 osób (54\%) miało powyżej 60 lat.

Pomiaru dokonano przy użyciu testu t-Studenta oraz testu ANOVA Kruskala Wallisa. Natomiast $\mathrm{w}$ celu poznania czynników socjo-demograficznych chorych do badania włączono ankietę własną. 
Analizę statystyczną przeprowadzono przy użyciu programu Statistica 10.0. Przyjęto poziom istotności $\mathrm{p} \leq 0,05$.

\section{Wyniki}

$\mathrm{Na}$ podstawie badań własnych można dostrzec, że największą liczbę punktów uzyskali respondenci w skali wskazującej na przekonanie, że ból kontrolowany jest przez czynniki wewnętrzne $(\mathrm{M}=18.90 \pm 5.014)$. Najczęściej wybieranymi odpowiedziami, dotyczącymi strategii radzenia sobie $\mathrm{z}$ bólem $\mathrm{w}$ tej grupie osób były: deklarowanie radzenia sobie $(M=16.33 \pm 3.999)$, katastrofizowanie $(\mathrm{M}=15.68 \pm 5.366)$ i zwiększona aktywność behawioralna $(\mathrm{M}=15.65$ \pm 3.999). Najmniej punktów badani uzyskali $w$ skali ignorowanie doznań $(\mathrm{M}=14.32 \pm 3.657)$. $\mathrm{W}$ tabeli 1 przedstawiono przekonania na temat bólu i strategie radzenia sobie z nim.

Tabela 1. Przekonania na temat bólu i strategie radzenia sobie $\mathrm{z}$ bólem $\mathrm{w}$ grupie badanej.

\begin{tabular}{|c|c|c|c|c|c|c|c|c|}
\hline zmienna & & M & SD & $\begin{array}{l}\mathbf{M i} \\
\mathbf{n}\end{array}$ & $\begin{array}{l}\text { Perce } \\
\text { ntyl } \\
10\end{array}$ & Me & $\begin{array}{l}\text { Perce } \\
\text { ntyl } \\
90\end{array}$ & $\begin{array}{l}\text { Ma } \\
\mathbf{x}\end{array}$ \\
\hline \multirow{3}{*}{$\begin{array}{l}\text { przekon } \\
\text { ania na } \\
\text { temat } \\
\text { bólu }\end{array}$} & $\begin{array}{l}\text { kontrolowany } \\
\text { przez czynniki } \\
\text { wewnętrzne }\end{array}$ & $\begin{array}{l}18 . \\
90\end{array}$ & $\begin{array}{l}5.0 \\
14\end{array}$ & $\begin{array}{l}7.0 \\
0\end{array}$ & 11.50 & $\begin{array}{l}20 . \\
00\end{array}$ & 24.50 & $\begin{array}{l}30 . \\
00\end{array}$ \\
\hline & $\begin{array}{l}\text { kontrolowany } \\
\text { przez lekarzy }\end{array}$ & $\begin{array}{l}15 . \\
33\end{array}$ & $\begin{array}{l}4.4 \\
33\end{array}$ & $\begin{array}{l}5.0 \\
0\end{array}$ & 8.00 & $\begin{array}{l}16 . \\
00\end{array}$ & 20.00 & $\begin{array}{l}24 . \\
00\end{array}$ \\
\hline & $\begin{array}{l}\text { kontrolowany } \\
\text { przez czynniki } \\
\text { zewnętrzne }\end{array}$ & $\begin{array}{l}14 . \\
97\end{array}$ & $\begin{array}{l}3.2 \\
62\end{array}$ & $\begin{array}{l}8.0 \\
0\end{array}$ & 9.50 & $\begin{array}{l}16 . \\
00\end{array}$ & 19.00 & $\begin{array}{l}21 . \\
00\end{array}$ \\
\hline $\begin{array}{l}\text { strategie } \\
\text { radzenia }\end{array}$ & $\begin{array}{l}\text { przewartościo } \\
\text { wanie doznań } \\
\text { bólu }\end{array}$ & $\begin{array}{l}14 . \\
68\end{array}$ & $\begin{array}{l}4.1 \\
68\end{array}$ & $\begin{array}{l}4.0 \\
0\end{array}$ & 10.00 & $\begin{array}{l}15 . \\
00\end{array}$ & 20.00 & $\begin{array}{l}27 . \\
00\end{array}$ \\
\hline $\begin{array}{l}\text { Soble } \mathrm{Z} \\
\text { bólem }\end{array}$ & $\begin{array}{l}\text { ignorowanie } \\
\text { doznań }\end{array}$ & $\begin{array}{l}14 . \\
32\end{array}$ & $\begin{array}{l}3.6 \\
57\end{array}$ & $\begin{array}{l}7.0 \\
0\end{array}$ & 10.00 & $\begin{array}{l}14 . \\
00\end{array}$ & 20.00 & $\begin{array}{l}23 . \\
00\end{array}$ \\
\hline
\end{tabular}




\begin{tabular}{|c|c|c|c|c|c|c|c|}
\hline $\begin{array}{l}\text { deklarowanie } \\
\text { radzenia sobie }\end{array}$ & $\begin{array}{l}16 . \\
33\end{array}$ & $\begin{array}{l}3.9 \\
99\end{array}$ & $\begin{array}{l}7.0 \\
0\end{array}$ & 11.00 & $\begin{array}{l}16 . \\
00\end{array}$ & 22.00 & $\begin{array}{l}24 . \\
00\end{array}$ \\
\hline odwracanie & 15. & 3.4 & 8.0 & & 15. & & 23. \\
\hline uwagi & 07 & 68 & 0 & 11.00 & 00 & 20.00 & 00 \\
\hline $\begin{array}{l}\text { zwiększona } \\
\text { aktywność } \\
\text { behawioralna }\end{array}$ & $\begin{array}{l}15 . \\
65\end{array}$ & $\begin{array}{l}3.9 \\
99\end{array}$ & $\begin{array}{l}9.0 \\
0\end{array}$ & 11.00 & $\begin{array}{l}15 . \\
00\end{array}$ & 21.00 & $\begin{array}{l}27 . \\
00\end{array}$ \\
\hline $\begin{array}{l}\text { modlenie się/ } \\
\text { pokładanie } \\
\text { nadziei }\end{array}$ & $\begin{array}{l}15 . \\
32\end{array}$ & $\begin{array}{l}4.4 \\
70\end{array}$ & $\begin{array}{l}5.0 \\
0\end{array}$ & 9.50 & $\begin{array}{l}15 . \\
50\end{array}$ & 20.50 & $\begin{array}{l}27 . \\
00\end{array}$ \\
\hline $\begin{array}{l}\text { katastrofizowa } \\
\text { nie }\end{array}$ & $\begin{array}{l}15 . \\
68\end{array}$ & $\begin{array}{l}5.3 \\
66\end{array}$ & $\begin{array}{l}6.0 \\
0\end{array}$ & 9.00 & $\begin{array}{l}15 . \\
00\end{array}$ & 23.00 & $\begin{array}{l}28 . \\
00\end{array}$ \\
\hline kontrola bólu & $\begin{array}{l}3.2 \\
8\end{array}$ & $\begin{array}{l}1.3 \\
79\end{array}$ & $\begin{array}{l}0.0 \\
0\end{array}$ & 2.00 & $\begin{array}{l}3.0 \\
0\end{array}$ & 5.00 & $\begin{array}{l}6.0 \\
0\end{array}$ \\
\hline $\begin{array}{l}\text { zdolność } \\
\text { zmniejszenia } \\
\text { bólu }\end{array}$ & $\begin{array}{l}2.9 \\
7\end{array}$ & $\begin{array}{l}1.3 \\
14\end{array}$ & $\begin{array}{l}0.0 \\
0\end{array}$ & 1.00 & $\begin{array}{l}3.0 \\
0\end{array}$ & 5.00 & $\begin{array}{l}6.0 \\
0\end{array}$ \\
\hline
\end{tabular}

Źródło: wynik badań własnych

Badania przeprowadzono wśród pacjentów po zabiegu kamicy pęcherzyka żółciowego oraz przepukliny pachwinowej. W grupie respondentów z kamicą pęcherzyka żółciowego, badani największą liczbę punktów uzyskali w skali wskazującej na przekonanie, że ból kontrolowany jest przez czynniki wewnętrzne $(\mathrm{M}=19.03 \pm 4.752)$. Najczęściej wybieranymi strategiami radzenia sobie $\mathrm{z}$ bólem $\mathrm{w}$ tej grupie osób były: deklarowanie radzenia sobie $(\mathrm{M}=16.93 \pm 4.299)$, odwracanie uwagi $(\mathrm{M}=15.77 \pm 3.014)$ o zwiększona aktywność behawioralna ( $\mathrm{M}=15.53 \pm 4.032)$. Najmniej punktów badani $\mathrm{z}$ kamicą pęcherzyka żółciowego $\mathrm{W}$ skali katastrofizowanie $(\mathrm{M}=14.50 \pm 1.848)$.

W grupie osób z przepukliną pachwinową, badani największą liczbę punktów uzyskali w skali wskazującej na przekonanie, że ból kontrolowany jest przez czynniki wewnętrzne $(\mathrm{M}=18.77 \pm 4.341)$. 
Najczęściej wybieranymi strategiami radzenia sobie $\mathrm{z}$ bólem $\mathrm{w}$ tej grupie osób były: katastrofizowanie $(M=16.87 \pm 5.673)$, zwiększona aktywność behawioralna $(\mathrm{M}=15.77 \pm 4.032)$ oraz deklarowanie radzenia sobie $(M=15.73 \pm 3.648)$. Najmniej punktów badani z przepukliną pachwinową wybierali strategię ignorowanie doznań $(\mathrm{M}=14.50 \pm 1.848)$.

Na podstawie badań można dostrzec, że rodzaj zabiegu nie okazał się istotnym czynnikiem różnicującym wyniki uzyskane przez respondentów $\mathrm{w}$ badanych skalach. W tabeli 2 przedstawiono przekonania i strategie radzenia sobie $\mathrm{z}$ bólem przez badanych poddanych leczeniu operacyjnemu w zależności od rodzaju zabiegu.

Tabela 2. Przekonania i strategie radzenia sobie $\mathrm{z}$ bólem przez badanych poddanych leczeniu operacyjnemu w zależności od rodzaju zabiegu.

\begin{tabular}{|c|c|c|c|c|c|c|c|}
\hline \multirow[t]{2}{*}{ Zmienna } & & \multicolumn{2}{|c|}{$\begin{array}{l}\text { kamica } \\
\text { pęcherzyka } \\
\text { żółciowego } \\
\mathrm{N}=30\end{array}$} & \multicolumn{2}{|c|}{ przepuklin } & $\mathrm{t}$ & \multirow[t]{2}{*}{$P$} \\
\hline & & M & SD & $\mathrm{M}$ & SD & & \\
\hline \multirow{3}{*}{$\begin{array}{l}\text { przekonani } \\
\text { a na temat } \\
\text { bólu }\end{array}$} & $\begin{array}{l}\text { kontrolowany } \\
\text { przez czynniki } \\
\text { wewnętrzne }\end{array}$ & $\begin{array}{l}19.0 \\
3\end{array}$ & $\begin{array}{l}4.75 \\
2\end{array}$ & $\begin{array}{l}18.7 \\
7\end{array}$ & $\begin{array}{l}5.34 \\
1\end{array}$ & $\begin{array}{l}0.2 \\
0\end{array}$ & $\begin{array}{l}0.83 \\
9\end{array}$ \\
\hline & $\begin{array}{l}\text { kontrolowany } \\
\text { przez lekarzy }\end{array}$ & $\begin{array}{l}14.7 \\
0\end{array}$ & $\begin{array}{l}4.26 \\
0\end{array}$ & $\begin{array}{l}15.9 \\
7\end{array}$ & $\begin{array}{l}4.58 \\
2\end{array}$ & $\begin{array}{l}- \\
1.1 \\
1\end{array}$ & $\begin{array}{l}0.27 \\
2\end{array}$ \\
\hline & $\begin{array}{l}\text { kontrolowany } \\
\text { przez czynniki } \\
\text { zewnętrzne }\end{array}$ & $\begin{array}{l}15.0 \\
3\end{array}$ & $\begin{array}{l}3.04 \\
5\end{array}$ & $\begin{array}{l}14.9 \\
0\end{array}$ & $\begin{array}{l}3.51 \\
7\end{array}$ & $\begin{array}{l}0.1 \\
6\end{array}$ & $\begin{array}{l}0.87 \\
6\end{array}$ \\
\hline $\begin{array}{ll}\text { strategie } & \\
\text { radzenia } & \\
\text { sobie } \quad \mathrm{z}\end{array}$ & $\begin{array}{l}\text { przewartościowa } \\
\text { nie doznań bólu }\end{array}$ & $\begin{array}{l}14.6 \\
0\end{array}$ & $\begin{array}{l}4.53 \\
8\end{array}$ & $\begin{array}{l}14.7 \\
7\end{array}$ & $\begin{array}{l}3.83 \\
9\end{array}$ & $\begin{array}{l}0.1 \\
5\end{array}$ & $\begin{array}{l}0.87 \\
8\end{array}$ \\
\hline
\end{tabular}




\begin{tabular}{|c|c|c|c|c|c|c|c|}
\hline bólem & ignorowanie & 14.6 & 3.96 & 13.9 & 3.35 & 0.7 & 0.46 \\
\hline & doznań & 7 & 0 & 7 & 8 & 4 & 3 \\
\hline & deklarowanie & 16.9 & 4.29 & 15.7 & 3.64 & 1.1 & 0.24 \\
\hline & radzenia sobie & 3 & 9 & 3 & 8 & 7 & 8 \\
\hline & & 15.7 & 3.01 & 14.3 & 3.79 & 1.5 & 0.11 \\
\hline & odwracanie uwagi & 7 & 4 & 7 & 2 & 8 & 9 \\
\hline & zwiększona & 15.5 & 4.03 & 15.7 & 4.03 & & 0.82 \\
\hline & $\begin{array}{l}\text { aktywnosc } \\
\text { behawioralna }\end{array}$ & 3 & 2 & 7 & 2 & $\begin{array}{l}0.2 \\
2\end{array}$ & 3 \\
\hline & modlenie się/ & 14.9 & 4.69 & 15.6 & 4.28 & 06 & 0.54 \\
\hline & $\begin{array}{l}\text { pokradanie } \\
\text { nadziei }\end{array}$ & 7 & 4 & 7 & 6 & $\begin{array}{l}0.6 \\
0\end{array}$ & 9 \\
\hline & lathctrofizowanis & 14.5 & 4.84 & 16.8 & 5.67 & 17 & 0.08 \\
\hline & 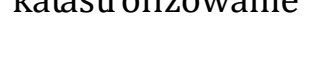 & 0 & 8 & 7 & 3 & $\begin{array}{l}1.1 \\
4\end{array}$ & 8 \\
\hline & lantrola hólu & 357 & 1.43 & 300 & 1.28 & 1.6 & 0.11 \\
\hline & Kontrola boiu & $3.5 /$ & 1 & 3.00 & 7 & 1 & 2 \\
\hline & zdolność & $? 00$ & 0.94 & 000 & 1.61 & & 0.84 \\
\hline & zmniejszenia bólu & 2.93 & 4 & 3.00 & 9 & $\begin{array}{l}0.1 \\
0\end{array}$ & 6 \\
\hline
\end{tabular}

Źródło: wynik badań własnych

\section{Dyskusja}

Opieka pooperacyjna nad pacjentem obejmuje holistyczne i zindywidualizowane podejście do problemów pacjenta. Badania prowadzone nad strategią radzenia sobie $\mathrm{z}$ bólem $\mathrm{w}$ oddziale chirurgii są wyjątkowo istotne, gdyż, dają możliwość na zmianę podejmowanych działań i wdrożenie takich rozwiązań, które są najwyżej oceniane przez odbiorców świadczeń. Umiejscowienie kontroli zdrowia, które mierzy siłę indywidualnych przekonań dotyczących kontrolowania sytuacji osobiście (czynniki wewnętrzne), przez wpływ lekarzy (siła 
innych) czy też przez przypadkowe zdarzenia ma bezpośredni wpływ na rodzaj strategii radzenia sobie z bólem. Pacjenci często tworzą indywidualne strategie radzenia sobie $\mathrm{z}$ bólem, bazując na dotychczasowych doświadczeniach oraz osobistych przekonaniach Uświadomienie choremu jego zasobów związanych z możliwością kontroli i oceny tego doznania, ułatwi sposób identyfikacji jego potrzeb oraz dostosowanie odpowiedniego rodzaju terapii. Umożliwi również edukację pacjenta oraz uświadomienie jego wpływu na swoje własne zdrowie.

Przeprowadzone badania $\mathrm{w}$ zakresie porównania umiejscawiania kontroli bólu i strategii radzenia sobie z bólem, rodzaj wykonanego zabiegu nie okazał się istotnym czynnikiem różnicującym wyniki uzyskane przez respondentów w powyższych aspektach. Pacjenci po operacji kamicy pęcherzyka żółciowego najczęściej deklarowali wybór strategii: deklarowanie radzenia sobie i odwracanie uwagi. Natomiast $\mathrm{w}$ przypadku przepukliny pachwinowej były to katastrofizowanie i zwiększona aktywność behawioralna.

Zielazny i współpracownicy badali przekonania na temat kontroli bólu oraz strategie radzenia sobie z bólem wśród pacjentów zakwalifikowanych do zabiegu operacyjnego. Badano 60 pacjentów Kliniki Neurologii w Gdańsku poddanych różnym zabiegom operacyjnym. Najczęściej osoby badane deklarowały radzenie sobie $\mathrm{z}$ bólem oraz wykorzystywały $\mathrm{w}$ tym zakresie strategię: modlenie się/pokładanie nadziei. Najrzadziej z kolei wskazywały na strategie: przewartościowywanie doznań oraz katastrofizowanie. Jednak były to bardzo małe różnice na granicy istotności statystycznej [6].

Szczudłowski zbadał 60 pacjentów po zabiegach chirurgicznych (pomostowanie naczyń wieńcowych, operacje naprawcze lub wymianę zastawek serca). Wyniki wykazały różne natężenia bólu wśród badanych pacjentów, a także małe różnice odnośnie strategii i sposobów radzenia sobie z bólem. Dominowało 
jednak katastrofizowanie oraz odwracanie uwagi (nieistotnie statystycznie) mając na uwadze płeć i wiek badanych [7].

Różnice $\mathrm{w}$ każdym $\mathrm{z}$ powyższych badań $\mathrm{w}$ korelacji z autorskimi wynikami badań mogą wynikać z różnorodności zmiennych branych pod uwagę oraz liczebności grup poddanych badaniom. Analizując te badania można określić wpływ poszczególnych czynników na strategie radzenia sobie $\mathrm{z}$ bólem pooperacyjnym. Literatura pozwala na porównanie czynników warunkujących reakcje pacjenta na ból pooperacyjny, tym samym dając informacje zwrotną o konieczności wdrażania nowych procedur w opiece nad pacjentem chirurgicznym.

\section{Wnioski}

Badania zostały przeprowadzone na grupie pacjentów po zabiegu kamicy pęcherzyka żółciowego oraz po zabiegu przepukliny pachwinowej. Obydwie grupy zostały skorelowane na podstawie strategii i przekonań radzenia sobie z bólem po zabiegu operacyjnym. Na podstawie przeprowadzonych badań można wywnioskować, że rodzaj zabiegu operacyjnego nie wpływał na istotne różnice $\mathrm{w}$ wyborze strategii i sposobów radzenia sobie z bólem przez badanych poddanych określonym zabiegom chirurgicznym.

\section{Zalecenia da praktyki pielęgniarskiej}

Badania prowadzone wśród pacjentów po zabiegach operacyjnych pozwalają na analizę możliwości radzenia sobie z bólem pooperacyjnym. Dodatkowo zmierzają do aktualizowania i poszerzania dotychczasowej wiedzy na opisywany temat. Opieka pooperacyjna nad pacjentem powinna 
opierać się na wiedzy, umiejętnościach oraz prezentowanej postawie zawodowej.

Pielęgniarki spośród wszystkich pracowników zespołu interdyscyplinarnego, sprawującego opiekę nad pacjentem mają najczęstszy $\mathrm{z}$ nim kontakt, stąd też istotna jest ich rola $\mathrm{w}$ skutecznym zwalczaniu bólu pooperacyjnego. Opieka pielęgniarska powinna być holistyczna, a jednocześnie zindywidualizowana na potrzeby pacjenta. Ponadto oczekuje się od personelu pielęgniarskiego wsparcia emocjonalnego i zapewnienia poczucia bezpieczeństwa.

\section{Bibliografia / Bibliography:}

1. Boon, N., Colledge, N., Davidson, B.: Choroby wewnętrzne. Tom 1. Wydawnictwo Elsevier Urban \& Partner, Wrocław 2009, s. 20-69.

2. Diener, H., Maier, Ch., Kubler, A.: Leczenie bólu. Wyd. I. Urban \& Partner, Wrocław 2005: s. 283-421.

3. Dobrogowski, J., Mayzner-Zawadzka, E., Drobnik, L., Kusza, K. Woroń, J., Wordliczek, J.: Uśmierzanie bólu pooperacyjnego - zalecenia. Ból 2008; 9: 9-22.

4. Mędrzycka-Dąbrowska, W. , Ogrodniczuk, M., Dąbrowski, S.: Udział pielęgniarki $\mathrm{w}$ procesie terapii bólu pooperacyjnego - część I. Anestezjologia i Ratownictwo 2012; 6: 332-338.

5. Misiołek, H., Mayzner-Zawadzka, E., Dobrogowski, J., Wordliczek, J.: Zalecenia 2011 postępowania w bólu ostrym i pooperacyjnym. Ból 2011; 12: 9-33. 
6. Zielazny, P., Uzdrowska, B., Błaszczyk, A., Zarzeczna-Baran, M. Stopień akceptacji choroby, przekonania na temat kontroli bólu oraz strategie radzenia sobie z bólem wśród pacjentów zakwalifikowanych do zabiegu $\mathrm{z}$ powodu choroby zwyrodnieniowej kręgosłupa Postępy Psychiatrii i Neurologii 2013; 22: 251-258.

7. Szczudłowski, B., Płaszewska- Żywko, L.: Lokalizacja i natężenie bólu u chorych po zabiegach kardiochirurgicznych. Pielęgniarstwo Chirurgiczne i Angiologiczne 2012; 4: 161-166. 